\title{
8 ANHANG
}

\section{INHALTSÜBERSICHT}

8.1 ERGEBNISSE: Intersektorale Prinzipien-, Kriterien- und Indikatoren-Sets für integratives nachhaltiges Wildtiermanagement im Biosphärenpark Wienerwald (Vollund Kurzversionen)

8.1.1 Jagd (Voll- und Kurzversion)

8.1.2 Forstwirtschaft (Voll- und Kurzversion)

8.1.3 Landwirtschaft (Voll- und Kurzversion)

8.1.4 Freizeit \& Erholung (Voll- und Kurzversion)

8.2 Interviewleitfaden der Experteninterviews

8.3 Fragebögen der Nutzerbefragungen

8.3.1 Fragebogen für Forstwirte

8.3.2 Fragebogen für Landwirte

8.3.3 Fragebogen für Reiter

8.3.4 Fragebogen für Mountainbiker und Wanderer

8.4 Karten

8.4.1 Verzeichnis der Kartenbeilagen

8.4.2 Kartenbeilagen

8.4.3 Verzeichnis der Datenurheber zu den Kartenbeilagen 